\title{
PENGUKURAN LOW WATER SPRING (LWS) DAN HIGH WATER SPRING (HWS) LAUT DENGAN METODE BATHIMETRIC DAN METODE ADMIRALTY
}

\author{
Nila Kurniawati Sunarminingtyas \\ Email: sunarminingtyas@gmail.com
}

\begin{abstract}
Abstrak : Pembangunan daerah pantai tidak terlepas dari sifat perarairan di daerah tersebut. Pengamatan pasang surut dilakukan untuk memperoleh data sifat dan fenomena perairan yang berbeda-beda di tiap tempat, tergantung topografi, letak geografis, dan sifat masing-masing lautan maupun karakteristik tempat tersebut.
\end{abstract}

Kata Kunci: bathimetric, admiralty

\section{PENDAHULUAN}

Survey hidrografi dilakukan untuk mendapatkan gambaran mengenai kondisi perairan setempat yang meliputi karakteristik pasang surut dan arus. Sehubungan hal tersebut maka pekerjaan yang dilakukan dalam survey hidrografi ini meliputi survey Bathimetric untuk mengetahui kedalaman laut dan survey Admiralty untuk pengamatan pasang surut dan pengamatan arus.

\section{TINJAUAN PUSTAKA}

\section{A. Survey Bathimetric}

Survey bathimetri merupakan survey yang dilakukan untuk mengukur dan mengamati kedalaman laut dengan menggunakan alat ukur kedalaman, sehingga dapat diperoleh gambaran mengenai bentuk dasar laut, posisi-posisi kerang ataupun posisi benda-benda yang dapat mengganggu alur pelayaran.

\section{B. Metode Admiralty}

Metode admiralty dilakukan untuk mengetahui jenis pasang surut. Data-data pasang surut yang terukur tersebut dapat diolah dengan menggunakan metode Admiralty untuk mendapatkan konstanta pasut $\left(\mathrm{K}_{1}, \mathrm{O}_{1}, \mathrm{M}_{2}, \mathrm{~S}_{2}, \mathrm{~N}_{2}\right)$ dengan koreksi konstanta pengali yang ditetapkan IOC (International Oceanographic Commision).
Dari konstanta-konstanta pasut tersebut dapat digunakan untuk mengetahui tipe pasut dengan rumus FORMZAL sebagai berikut :

$$
\begin{aligned}
& \mathrm{F}=\begin{array}{l}
A(M 1)+A(O 1) \\
\text { Dimana : }
\end{array} \mathrm{F} \text { adalah nilai formzal } \\
& \text { A adalah amplitudo }
\end{aligned}
$$

K1 dan O1 adalah konstanta pasut harian utama

M2 dan S2 adalah konstanta pasut ganda utama

Berdasarkan hasil perhitungan, akan diketahui tipe pasang surut air, Secara umum pasut diberbagai daerah dapat dibedakan dalam empat tipe, yaitu (Ongkosongo, 1989) :

1) Pasang surut harian ganda ( semi diurnal tide )

Dalam satu hari terjadi dua kali air pasang dan dua kali air surut dengan tinggi yang hampir sama dan pasang surut terjadi secara berurutan secara teratur. Nilai Formzahl $0<\mathrm{F}<$ 0,25

2) Pasang surut harian tunggal (diurnal tide )

Dalam satu hari terjadi satu kali pasang dan satu kali surut. Periode 
pasang surut adalah 24 jam 50 menit. Nilai Formzahl 3,0 < F

3) Pasang surut campuran condong ke harian ganda (mixed tide prevailing semi diurnal)

Dalam satu hari terjadi dua kali air pasang dan dua kali air surut, tetapi tinggi dan periodenya berbeda. Nilai Formzahl 0,25 $<$ F $<1,50$

4) Pasang surut campuran condong ke harian tunggal ( mixed tide prevailing diurnal)

Dalam satu hari terjadi satu kali pasang dan satu kali surut, tetapi kadang-kadang untuk sementara waktu terjadi dua kali pasang dan dua kali surut dengan tinggi dan periode yang sangat berbeda. Nilai Formzahl $1,50<\mathrm{F}<3,0$.

\section{Survey Dengan Metode Barthimetric} Dan Perhitungan Dengan Metode Admiralty

\section{A. Survey dengan Metode Bathimetric}

Alat-alat yang digunakan untuk melaksanakan pekerjaan survey ini meliputi

- 1 (satu) unit Echosounder Raytheon

- GPSMAP 178 C GARMIN SOUNDER

- 2 (satu) unit Theodolite T2

- 3 (tiga) unit Handy Talky

- 1 (satu) unit Perahu Motor

- 1 (satu) unit Compass Lapangan

Alat Bantu lainnya

Sistem positioning dan navigasi kapal menunjukkan dan merekam posisi kapal serta kedalaman laut yang dilakukan secara otomatis setiap 7 detik dengan jarak 10 meter dengan menggunakan alat ukur echosounding merk Raytheon dan GPS MAP 178c Sounder sebagai kontroller. Selanjutnya pemrosesan dilakukan dengan system komputer menggunakan program (Autocad Land).
Data posisi kapal tereka, otomatis setiap 7 detik pada sistem komputer dan kedalaman terekam pada kertas echopaper. Lintasan dilakukan secara sistematis dengan interval $10 \mathrm{~m}$ mengikuti garis rencana pembangunan pelabuhan (Dermaga), sehingga akan diperoleh gambaran keterwakilan

Hasil pengukuran yang terekam dalam Echopaper direduksi terhadap kedudukan air surut terendah (LWS) sesuai hasil pengamatan pasang surut yang telah dilaksanakan.

\section{B. Hasil perhitungan Pasang Surut Metode Admiralty}

Hasil Perhitungan Pasang Surut selama 15 hari ( piantan) dengan metode Admiralty disajikan pada tabel-tabel berikut ini :

Data Pasang Surut :

Tabel 1. Analisa Harmonik Pasang Surut laut Muara badak Kab. Kuta Kartanegara Metode Admiralty

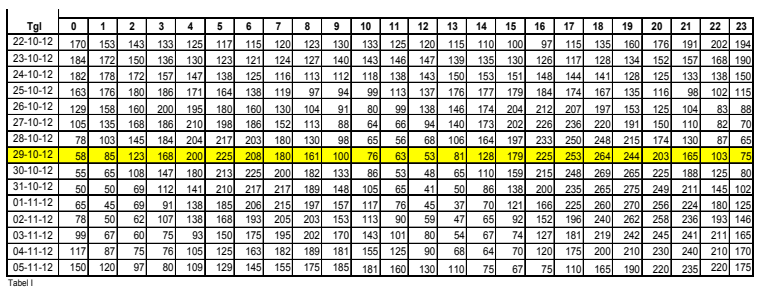

Grafik Pasang Surut:

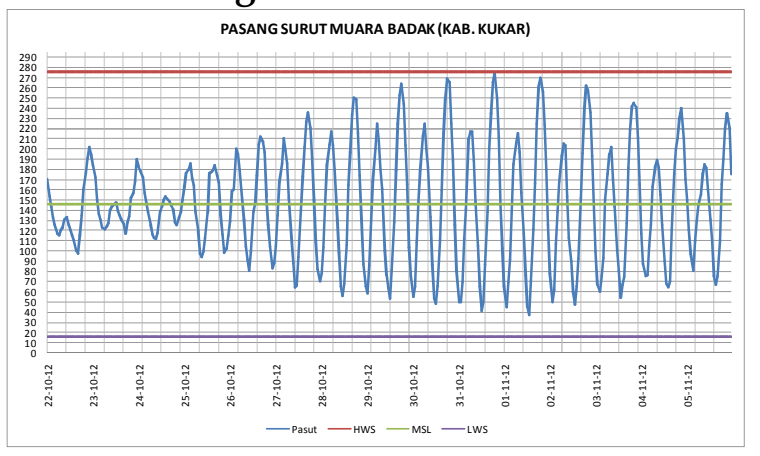




\section{ANALISA HASIL}

Dari data pasang surut perairan Kaimer selama 15 Piantan, telah dihitung Konstanta tabiat-tabiat pasang surut berdasarkan metoda Admiralty dengan hasil sebagi berikut :

Tabel 2. Konstanta Pasang Surut

\begin{tabular}{|c|c|c|c|c|c|c|c|c|c|c|}
\hline & S0 & M2 & S2 & N2 & K1 & 01 & M4 & MS4 & K2 & P1 \\
\hline A $($ (Cm) & 146 & 60 & 41 & 6 & 21 & 14 & 1 & 1 & 10 & 7 \\
\hline $\mathrm{g}(0)$ & 338 & 27 & 297 & 312 & 23 & 196 & 4 & 27 & 312 \\
\hline \multicolumn{3}{|c|}{ Berdasarkan } & 312 & \multicolumn{7}{c|}{ harmonis } \\
\hline
\end{tabular}
tersebut diatas dibuat analisa dan uraianuraian sebagai berikut :

\section{Sifat/Type Pasang Surut}

$(\mathrm{AK} 1+\mathrm{AO} 1) /(\mathrm{AM} 2+\mathrm{AS} 2)=0,35$

Karena $=0,25<(\mathrm{AK} 1+\mathrm{AO} 1) /(\mathrm{AM} 2+\mathrm{AS} 2)<$ 1,50

Type Pasutnya adalah Pasang Surut Campuran condong keharian Ganda

\section{Perhitungan Muka Surutan}

gK1 + gO1 - gM2 mempunyai harga diantara 347 - 13 dan 167 - 193 Disini $\mathrm{gK} 1+\mathrm{gO} 1-\mathrm{gM} 2=$ $311,8+$ $23,3-337,5=357,6$

Maka diperoleh kesimpulan bahwa Air Tinggi dan Air Rendah pada pasang purnama dari kedua kelompok pasang akan jatuh bersamaan.

\section{Perhitungan Air Tinggi (AT)}

a. Kedudukan gelombang-gelombang pasang $\mathrm{K} 1$ dan $\mathrm{K} 2$

Phase $\mathrm{K} 2=2 \times$ phase $\mathrm{K} 1+2 \mathrm{gK} 1-\mathrm{gK} 2$ $-180$

180

$$
=2 \times \text { phase } \mathrm{K} 1+623,6-26,6-
$$

$$
=2 \times \text { phase } \mathrm{K} 1+(-417)=57,0
$$

Pada waktu terjadi ARK1 (phase K1 = 180), maka phase $K 2=-57$
Karena gelombang pasang K2 selalu mempengaruhi K1, maka ATK2 jatuh pada :

$$
\frac{30}{30,06} \times 1 \text { jam }=10,1 \text { jam sebelum }
$$

ARK1

Sedangkan ARK2 akan jatuh pada :

$$
\begin{aligned}
& \frac{330-180}{30,08} \times 1 \text { jam }=4,1 \text { jam sesudah } \\
& \text { ARK1 }
\end{aligned}
$$

b. Kedudukan gelombang-gelombang pasang M2, K1 dan O1

Phase M2 = Phase $\mathrm{K} 1+$ phase $\mathrm{O} 1+\mathrm{gK} 1+$ $\mathrm{gO} 1-\mathrm{gM} 2$

$$
=\text { Phase } \mathrm{K} 1+\text { phase } \mathrm{O} 1+311,8+
$$

$23,3-338$

$$
\text { = Phase } \mathrm{K} 1+\text { phase } \mathrm{O} 1+357,6
$$

Pada saat Koinsidensi ARK1 dan ARO1, phase M2 = 357,6, maka ARM2 jatuh pada

$$
\frac{357,6-180}{29,98} \times 1 \text { jam }=6,1 \text { jam }
$$

sebelum ARK1

Pada saat Koinsidensi ARK1 dan ARM2, phase $\mathrm{O} 1=-357,6$, jadi $\mathrm{ARO} 1$ jatuh pada

$$
\frac{180-2}{13,94} \quad \text { x } 1 \text { jam }=12,7 \text { jam sebelum }
$$
ARK1

\section{a. Analisa Kombinasi}

Hasil kombinasi memberikan bahwa air tinggi tertinggi yang disebabkan oleh kombinasi gelombang-gelombang M2, K1, O1 dan K2 adalah 68,0 Cm diatas Duduk Tengah.

b. Pengaruh S2 
Apabila ATS2 jatuh bersamaan dengan keempat gelombang diatas (K1,O1, K2 dan M2) maka muka air tinggi akibat K1, O1, M2 dan M2 menjadi setinggi $=$

$68,0+51,5=109,5 \mathrm{Cm}$ di atas Duduk Tengah.

c. Pengaruh gelombang pasang P1

Phase S2 = Phase P1 + phase K1 + gK1 +

$$
\begin{aligned}
& \mathrm{gP} 1-\mathrm{gS} 2 \\
& =\text { Phase } \mathrm{P} 1+\text { phase } \mathrm{K} 1+311,8 \\
& +311,8-26,6 \\
& =\text { Phase } \mathrm{P} 1+\text { phase } \mathrm{K} 1+237
\end{aligned}
$$

Apabila ATS2 dan ATK1 jatuh bersamaan, maka phase $\mathrm{P} 1=103.1$ dan jatuh pada :

$$
\frac{273-180}{14,96} \times 1 \text { jam }=3,8 \text { jam sesudah }
$$

AT-nya sendiri

Pengaruh gelombang ini akan mempertinggi air tinggi sebesar 4,3, sehingga air tertinggi yang disebabkan oleh, Pasut M2, S2, K1, O1, K2 dan P1 adalah :

$(109,5+4,3)=113,8 \mathrm{Cm}$ di atas Duduk Tengah.

d. Pengaruh gelombang-gelombang N2, M4 dan MS4

Gelombang pasut ini dapat memperendah ataupun mempertinggi kedudukan AT. Dalam hal ini diambil factor yang memperendah kedudukan Ait Tinggi, sehingga kedudukan Air Tinggi Perbani (HWS) yang disebabkan oleh 9 gelombang utama Pasut (M2, S2, K1, O1, K2, K1, M4 dan MS4) adalah $=(113,8+8,3$ ) $=122,1$ diatas Duduk Tengah, ditambah factor keamanan sebesar $9 \mathrm{Cm}$, Maka Air Tinggi Purnama Menjadi $=130 \mathrm{~cm}$.

Berdasarkan seluruh data yang didapatkan dari hasil survey dan perhitungan, dapat dirangkum pada gambar berikut ini:

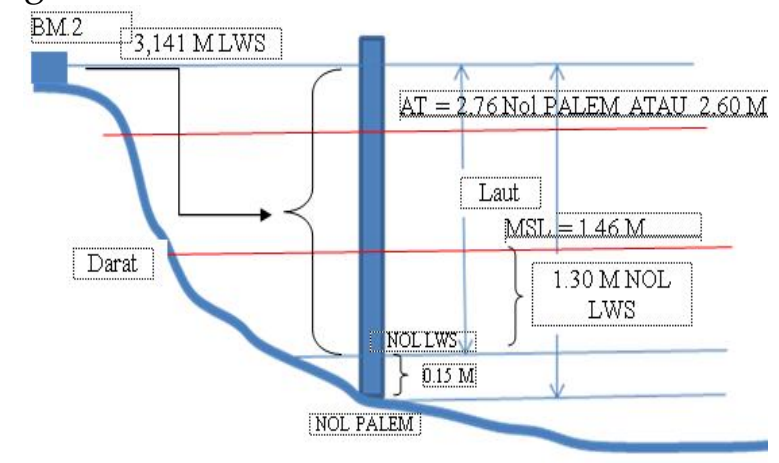

Dimana

AT : Air Tinggi berdasarkan perhitungan

Selanjutnya untuk menyatakan elevasi setiap koordinat di lokasi Muara Badak akan digunakan referensi sebagai berikut:

$>$ Kedudukan air Surut Terendah (LWS)

: $0.00 \mathrm{~m}$ LWS atau $-0,16 \mathrm{~m} 0$ Palem

$>$ Kedudukan Air Rata-rata: 1,30 m LWS atau $1.46 \mathrm{~m} 0$ Palem

$>\quad$ Kedudukan Air Pasang Tertinggi (HWS): $2.60 \mathrm{~m}$ LWS atau 2,76 m 0 Palem

\section{Pengamatan Arus}

Pengamatan arus dimaksudkan untuk mendapatkan gambaran ataupun perilaku arus diperairan setempat, sehingga dapat diketahui kecepatan dan arah arus yang dominan. Alat yang digunakan untuk melakukan pengamatan ini adalah current meter.

Pengamatan arus dilakukan selama 48 jam secara terus menerus pada tiga lapisan masing-masing kedalaman $0.2,0.6$ dan 0.8 dari kedalaman dasar laut yang ditinjau, dengan interval waktu pembacaan tiap 1 jam. Dari hasil pengamatan yang telah dilakukan, maka diperoleh kecepatan dan arah arus dominan di perairan Pelabuhan Muara badak, sebagai berikut: 
Tabel 3. Kecepatan dan arah arus pada saat Spring Tide

\begin{tabular}{|l|l|l|l|l|} 
Lokasi & Kedalaman & $\begin{array}{l}\text { Arah } \\
\text { Dominan }\end{array}$ & $\begin{array}{l}\text { Kecepatan } \\
\text { Maximum } \\
(\mathbf{m} / \mathrm{dtk})\end{array}$ & $\begin{array}{l}\text { Kecepatan } \\
\text { Minimum } \\
(\mathbf{m} / \mathrm{dtk})\end{array}$ \\
\hline \multirow{3}{*}{$\mathrm{S} 1$} & $0,2 \mathrm{~d}$ & $\mathrm{TL}$ & 0.364 & 0.000 \\
& $0,6 \mathrm{~d}$ & $\mathrm{TL}$ & 0.350 & 0.000 \\
& $0,8 \mathrm{~d}$ & $\mathrm{TL}$ & 0.345 & 0,000 \\
\hline \multirow{2}{*}{$\mathrm{S} 2$} & $0,2 \mathrm{~d}$ & $\mathrm{TL}$ & 0.363 & 0.000 \\
& $0,6 \mathrm{~d}$ & $\mathrm{TL}$ & 0.343 & 0.000 \\
& $0,8 \mathrm{~d}$ & $\mathrm{TL}$ & 0.332 & 0,000 \\
\hline
\end{tabular}

Tabel 4. Kecepatan dan arah arus pada saat Neap Tide

\begin{tabular}{|l|l|l|l|l|}
\hline Lokasi & Kedalaman & $\begin{array}{l}\text { Arah } \\
\text { Dominan }\end{array}$ & $\begin{array}{l}\text { Kecepatan } \\
\text { Max. (m/dtk) }\end{array}$ & $\begin{array}{l}\text { Kecepatan } \\
\text { Min. (m/dtk) }\end{array}$ \\
\hline \multirow{2}{*}{ N1 } & $0,2 \mathrm{~d}$ & $\mathrm{~B}$ & 0.393 & 0.000 \\
& $0,6 \mathrm{~d}$ & $\mathrm{~B}$ & 0.390 & 0.000 \\
& $0,8 \mathrm{~d}$ & $\mathrm{~B}$ & 0.377 & 0,000 \\
\hline \multirow{3}{*}{ N2 } & $0,2 \mathrm{~d}$ & $\mathrm{~B}$ & 0.379 & 0.000 \\
& $0,6 \mathrm{~d}$ & $\mathrm{~B}$ & 0.338 & 0.000 \\
& $0,8 \mathrm{~d}$ & $\mathrm{~B}$ & 0.325 & 0,000 \\
\hline
\end{tabular}

\section{SIMPULAN}

Berdasarkan hasil pengamatan dengan menggunakan alat ukur echosounding merk Raytheon dan GPS MAP 178c Sounder yang kemusian diproses dengan metode Bathimetric serta Metode Admiralty didapatkan kedudukan air pada Kawasan Perikanan Muara Badak Kabupaten Kutai Kartanegara sebagai berikut :

- Kedudukan air Surut Terendah (LWS) : $0.00 \mathrm{~m}$ LWS atau -0,16 m 0 Palem

- Kedudukan Air Rata-rata 1,30 m LWS atau $1.46 \mathrm{~m} 0$ Palem

- Kedudukan Air Pasang Tertinggi (HWS) : $2.60 \mathrm{~m} \mathrm{LWS} \mathrm{atau} \mathrm{2,76} \mathrm{m} 0$ Palem

\section{DAFTAR PUSTAKA}

[1] Badan Pusat Statistik Kutai Kartanegara, Kecamatan Kota Bangun Dalam Angka, 2011
[2] Badan Pusat Statistik Kutai Kartanegara, Kabupaten Kutai Kartanegara, 2011

[3] Cetin M. et al (2009) Investigation on Accuracies of Real Time Kinematic GPS for GIS

[4] Milbert, D.G., and Hess, K.W., 2001, Combination of topography and bathymetry through application of calibrated vertical datum transformations in the Tampa Bay region, in Proceedings, Coastal GeoTools '01, Charleston, South Carolina, January 8-11， 2001 (CDROM), NOAA/CSC/20114-CD, NOAA Coastal Services Center, Charleston, South Carolina.

[5] Soewarno, 1995, Hidrologi Aplikasi Metode Statistik untuk Analisa Data Jilid 1, NOVA, Bandung.

[6] Thurman, H. V. (1997), Introductory Oceanography, New Jersey, USA: Prentice Hall College

[7] Andrews (2001) NAVSTAR dari http://www.spaceandtech.com/spaced ata/constellations/navstargps_consum.shtml

[8] Arzu E. et al (2004) Mapping the Sea Bottom Using RTK GPS and LeadLine in Trabzon Harbor dari http://www.fig.net/pub/athens/papers /wsh3/WSH3_4_Ererer_Gokalp.pdf

[9] http://www.mdpi.com/2072$\underline{4292 / 1 / 1 / 22 / p d f}$ 